\title{
THE MOTOR EVOKED POTENTIAL IN AIDS AND HAM/TSP
}

\section{State of the evidence}

\author{
Fidias E. Leon-Sarmiento', Mohamed Elfakhani ${ }^{2}$, Nash N. Boutros ${ }^{2}$
}

\begin{abstract}
Objective: We aimed to better understand the involvement of the corticospinal tract, assessed by non-invasive transcranial stimulation, in order to determine the actual involvement of the motor system in patients with HAM/TSP and AIDS. Method: An exhaustive MEDLINE search for the period of 1985 to 2008 for all articles cross-referenced for "HTLV-I, HTLV-II, HTLV-III and HIV, HIV1, HIV2, evoked potential, motor evoked potential, high voltage electrical stimulation, transcranial magnetic stimulation, magnetic stimulation, corticomotor physiology, motor pathways, acquired immunodeficiency syndrome, AIDS, SIDA, tropical spastic paraparesis, HTLV-I-associated myelopathy, HAM, TSP, and HAM/TSP" were selected and analysed. Results: Eighteen papers published in English, Spanish, Portuguese, French and Japanese were identified. Only the central motor conduction time has been analyzed in seropositive patients to human retroviruses. The investigations done on HAM/TSP support the involvement of the pyramidal tract mainly at lower levels, following a centripetal pattern; in AIDS, such an involvement seems to be more prominent at brain levels following a centrifugal pattern. Conclusion: The central motor conduction time abnormalities and involvement differences of the corticospinal tract of patients with AIDS and HAM/TSP dissected here would allow to re-orient early neurorehabilitation measures in these retroviruses-associated neurodegenerative disorders. Besides this, more sophisticated and sensitive non-invasive corticospinal stimulation measures that detect early changes in thalamocortical-basal ganglia circuitry will be needed in both clinically established as well as asymptomatic patients at times when the fastest corticospinal fibers remain uninvolved.
\end{abstract}

KEY WORDS: AIDS, HAM/TSP, HIV, HTLV-I, transcranial magnetic stimulation, non-invasive transcranial stimulation, pyramidal tract.

\section{El potencial evocado motor en SIDA y HAM/PET}

Resumen - Objetivo: Investigar el compromiso del tracto piramidal, evaluado por estimulación trascranial no invasiva, en pacientes afectados por SIDA y HAM/TSP. Método: Se realizó una búsqueda en la base de datos MEDLINE, que abarcó el período de 1985 a 2008; se incluyeron los términos "HTLV-I, HTLV-II, HTLV-III and HIV, HIV1, HIV2, evoked potential, motor evoked potential, high voltage electrical stimulation, transcranial magnetic stimulation, magnetic stimulation, corticomotor physiology, motor pathways, acquired immunodeficiency syndrome, AIDS, SIDA, tropical spastic paraparesis, HTLV-I-associated myelopathy, HAM, TSP, and HAM/ TSP". Resultados: Se obtuvieron 18 artículos publicados en inglés, español, portugués, francés y japonés. El tiempo de conducción central es el único parámetro que se ha estudiado en individuos seropositivos a retrovirus humanos. Las investigaciones hechas en HAM/PET apoyan el compromiso del tracto piramidal, principalmente a nivel dorso-lumbar, de manera centrípeta. En SIDA, el compromiso parece ser mas prominente a nivel cortical, siguiendo un patrón centrifugo. Conclusion: El conocer las diferencias en el compromiso

\footnotetext{
'Unidad de Trastornos del Movimiento y Neurorehabilitacion, Seccion de Neurologia, Fundacion Santa Fe, Bogota, Colombia; Mediciencias Research Group, Universidad Nacional, Bogota, Colombia; ${ }^{2}$ Department of Psychiatry and Behavioral Neuroscience, Wayne State University, Detroit, Ml.

This study was supported by a federal grant RO1 DA019055 (NN Boutros) and a diversity supplemental award (FE Leon-Sarmiento). The project was also partially supported by the Joe Young State of Michigan Appropriation to the Department of Psychiatry and Behavioral Neuroscience of Wayne State University.
}

Received 14 June 2009, received in final form 18 September 2009. Accepted 22 September 2009.

Dr. Fidias E. Leon-Sarmiento - Mediciencias Research Group, Carrera 15 No. $73-57$ (201), Bogota, Colombia. E-mail: feleones@gmail.com 
y anormalidades del tracto corticoespinal de los pacientes con SIDA y HAM/TSP podrán ser útiles para reorientar la neurorehabilitación temprana en estos desórdenes neurodegenerativos asociados a retrovirus. De otro lado, evaluaciones mas sensibles y sofisticadas del sistema piramidal, que permitan detectar cambios tempranos en los circuitos talamocorticoganglionicos serán mandatarios de realizar a partir de la fecha, bien sea que los individuos estén asintomáticos o no, en estadios clínicos donde las fibras corticoespinales rápidas no estén aun comprometidas.

PALABRAS-CLAVES: AIDS, HAM/TSP, HIV, HTLV-I, trascranial magnetic stimulation, non-invasive transcranial stimulation, pyramidal tract.

HTLV-I and HIV, initially termed HTLV-III', are considered the exogenous retroviruses most pathogenic to humans ${ }^{2,3}$. HTLV-I was associated, in 1985, with a neurological disorder characterized by walking difficulties, sphincter dysfunction and spasticity affecting mainly the lower limbs (LL) and called tropical spastic paraparesis (TSP) in the West Indies ${ }^{4}$. Simultaneously, Osame et al. ${ }^{5}$ found a similar association with a myelopathy endemic around southern Japan and called it HTLV-I associated myelopathy (HAM). Shortly following, it was recognized that these disorders were the same clinical entity ${ }^{6}$. Over the years, it has been increasingly recognized that the neural involvement of HAM/TSP is more widespread than initially thought, reaching supraspinal areas of the central nervous system $(\mathrm{CNS})^{7-12}$. HIV, on the other hand, has been linked to a number of pathologies, most of which are considered due to opportunistic infections associated with different clinical pictures of immunodeficiency, neural involvement being an important aspect at the cortical and subcortical levels ${ }^{2,3,13}$. In 1985, near the beginning of the HIV era, it was also found that early HIV seroconversion affects the spinal cord leading to clinically progressive spastic paraparesis and sensory ataxia ${ }^{13-15}$. Interestingly enough, also in 1985 , it became possible to study the human corticospinal tract using a technique called transcranial magnetic stimulation (TMS) $)^{16}$. When a large current pulse is sent through a coil, it penetrates the skull with much less discomfort than that produced by high voltage electrical stimulation $(\mathrm{HIVES})^{17}$, used initially to probe the human corticospinal tract in intact brain ${ }^{18}$. Electromagnets placed on the scalp generate magnetic field pulses of about 100 घs and are approximately $2.0 \mathrm{~T}$ in strength; when applied to motor cortex, the descending volleys stimulate corticospinal pathways allowing for recording activity in the corresponding muscles by means of surface or needle electrodes ${ }^{19,20}$.

Different applications have been developed to study the CNS using TMS. Among these, central motor conduction time (CMCT) has been investigated since the beginning of TMS research using single pulses ${ }^{21,22}$. CMCT is defined as the difference in the onset latency between the MEPs elicited by scalp and those elicited by cervical stimulation and/or the onset latency difference between scalp and lumbar stimulation which is measured for upper limbs (UL) and/or LL. Thoracic CMCT is defined by subtracting UL-CMCT from LL-CMCT. More sophisticated applications have emerged over time including pairs and trains of stimuli that have allowed for increasing our knowledge of neural behavior and connections as well as its plastic modulation ${ }^{19,23}$.

In order to determine the actual clinical and subclinical involvement of the motor system in patients affected by exogenous retroviruses and the clinical correlates, if any, we examined the literature in which at least one of these non-invasive brain stimulation techniques (HIVES, TMS or both) was used to examine patients with AIDS and HAM/TSP. The results demonstrated selective effects of HTLV-1 and HIV in the corticospinal tract of affected people. Such findings might be helpful in defining future research in these neurodegenerative disorders.

\section{METHOD}

An exhaustive MEDLINE search was performed for the period of 1985 to 2008 for all articles cross-referenced for "HTLV-I, HTLV-II, HTLV-III and HIV, HIV1, HIV2". Additional searches were conducted using the terms, "evoked potential, motor evoked potential, high voltage electrical stimulation, transcranial magnetic stimulation, magnetic stimulation, corticomotor physiology, motor pathways, acquired immunodeficiency syndrome, AIDS, SIDA, tropical spastic paraparesis, HTLV-I-associated myelopathy, HAM, TSP, and HAM/TSP". Articles referenced in these articles having a motor evoked potential (MEP) description were also reviewed and review articles were used to identify additional original research articles. Papers published in English, Spanish, Portuguese, French and Japanese were analyzed. The following information was identified from each article: number of patients, number of controls, serological state, clinical stage of patients and neurological involvement. Regarding the MEP, latencies and amplitudes were considered and the CCMT was taken into account. Other more sophisticated TMS measures obtained with both single and paired stimuli, if any, were also included.

\section{RESULTS}

Eighteen papers were found reporting MEP values from HTLV-I and HIV positive patients, and only the 
Table. Summary of non-invasive transcranial stimulation studies done in patients seropositive to the exogenous retrovirus HTLV-I and HIV.

\begin{tabular}{|c|c|c|c|c|c|}
\hline Reference & MI & NP & TS & PB & LP \\
\hline Hugon et al. $1987^{41}$ & TSP' & 7 & HIVES & Ivory Coast & $E$ \\
\hline Hugon et al. $1989^{35}$ & TSP & 3 & HIVES & Ivory Coast & $E$ \\
\hline Ugawa et al. $1988^{34}$ & $\mathrm{HAM} / \mathrm{TSP}$ & 4 & HIVES & Japan & $\mathrm{E}$ \\
\hline Ugawa et al. $1988^{40}$ & $\mathrm{HAM} / \mathrm{TSP}$ & 4 & HIVES & Japan & J \\
\hline Tomita et al. $1989^{36}$ & $\mathrm{HAM} / \mathrm{TSP}$ & 8 & HIVES & Japan & $E$ \\
\hline Tomita et al. $1989^{37}$ & $\mathrm{HAM} / \mathrm{TSP}$ & 7 & HIVES & Japan & $E$ \\
\hline Young et al. $1998^{28}$ & HAM/TSP & 18 & TMS & Jamaica & $\mathrm{E}$ \\
\hline Suga et al. $1999^{38}$ & $\mathrm{HAM} / \mathrm{TSP}$ & 21 & TMS & Japan & $E$ \\
\hline Hashimoto et al. $2000^{30}$ & HAM/TSP & 4 & TMS & Japan & $\mathrm{E}$ \\
\hline Shimizu et al. $2001^{39}$ & $\mathrm{HAM} / \mathrm{TSP}$ & 13 & TMS & Japan & $E$ \\
\hline Andrade $2005^{29}$ & $\mathrm{HAM} / \mathrm{TSP}$ & 42 & TMS & Brazil & $P$ \\
\hline Zandrini et al. $1990^{31}$ & AIDS & 58 & TMS & NR & $\mathrm{E}$ \\
\hline Moglia et al. $1991^{* 25}$ & AIDS & 71 & TMS & NR & $E$ \\
\hline Parisi et al. $1992^{32}$ & AIDS & 40 & TMS & NR & $\mathrm{E}$ \\
\hline McAllister et al. $1992^{27}$ & AIDS & 44 & TMS & NR & $\mathrm{E}$ \\
\hline Arendt et al. $1992^{24}$ & AIDS & 42 & TMS & NR & $\mathrm{E}$ \\
\hline Grapperon et al. $1993^{43}$ & AIDS & 28 & TMS & NR & $\mathrm{F}$ \\
\hline
\end{tabular}

MI: medical illness; NP: number of patients; TS: type of stimulation; PB: place of birth; LP: language of paper's publication; E: english; F: french; J: japanese; P: portugues; NR: not reported; 'one patient had HAM; *it seems that some of the patients investigated by mean of TMS were also studied with HIVES; however, no clear description of it was done in the original publication.

CMCT has been investigated. Five papers used HIVES only in HTLV-I affected patients, one paper investigated both HIVES and TMS in a group of HIV patients and the remainder used TMS only (Table). All HTLV-I positive subjects had clinically (symptomatic) established HAM/TSP. In HIV research, the MEP of neurologically symptomatic as well as asymptomatic HIV positive patients were studied. When both types of patients were investigated, their data were pooled and analyzed all together by some groups; thus, it was not possible to know correlations of neurological complications, if any, in the measures reported as a group ${ }^{24,25}$. Only one paper on HIV reported motor threshold measurements, but actual values were not giv$\mathrm{en}^{24}$. Two papers, one on HIV and another on HTLV-I, took into account the height of subjects, an important confounding factor in CMCT measurement ${ }^{21,26-28}$. The MEPs obtained by TMS were investigated in three groups of HIV patients and in two groups of HTLV-I patients, while subjects performed voluntary muscle contractions of target muscles ${ }^{25,27,29-31}$; of these, two HIV groups and one HTLV-I group were found abnormal. Technical information on type of coils, place of stimulation and recording was incompletely described, so further analysis on this issue could not be undertaken. From the papers published, it could be said that in approximately 131 HAM/TSP and 404 HIV positive patients, the pyramidal tract was investigated by means of non-invasive transcranial stimulation.
Two papers reported MEP in HIV positive individuals but did not give the actual number of patients and controls investigated ${ }^{27,32}$. Only four papers reported the serological test used for defining HTLV-I and HIV positivity and no papers looked for possible cross-reactions ${ }^{2,33}$ with other germens present, sometimes, in some patients. Actual pictures of MEP findings on HTLV-I positive patients were presented by Ugawa et al. ${ }^{34}$, Hugon et al. ${ }^{35}$, Tomita et al. ${ }^{36,37}$ and Hashimoto et al. ${ }^{30}$ on HTLV-I positive patients, and on HIV positive patients by Arendt et al. ${ }^{24}$ only.

\section{HTLV-I}

CMCT was significantly prolonged in HAM/TSP subjects living in Jamaica, by $96 \%$ and $41 \%$ in the LL and upper limbs respectively ${ }^{28}$. This prolongation was significant in moderate disease stage, and mostly in UL with no correlation with symptom duration. Prolongation of MEP latencies was greater in earlier stages of disease probably associated with loss of fibers in the descending pathways ${ }^{28}$. MEP amplitudes from patients were lower than controls in LL. A study done in Japanese patients ${ }^{38}$ showed prolongation of MEP in $73.8 \%$ of LL and $17.6 \%$ of UL without correlation with clinical findings nor with central conduction sensory time either, suggesting that corticospinal and posterior columns involvement are independent lesions $^{38}$. Opposite to this, Shimizu et al..$^{39}$ found, also in Japanese patients, that CMCT in LL and UL were significant- 
ly prolonged and correlated with central motor conduction sensory time from LL and UL. The CMCT in UL correlated with the severity of disease which was interpreted as a result of the rostro-caudal severity of disease ${ }^{39}$. Likewise, there was a correlation of thoracic and LL CMCT with $\mathrm{F}$ wave $/ \mathrm{M}$ wave amplitude ratio from $\mathrm{LL}$ interpreted as disinhibition of the anterior horn cells in patients with HAM/TSP ${ }^{39}$. Out of 42 Brazilian patients investigated with TMS, 37 had an abnormal MEP; all of them had LL abnormalities ${ }^{29}$ either alone or in combination with UL abnormalities. No correlation was found with disease duration. This study also found a very close frequency of abnormalities in the posterior spinal cord using SSEP. Hashimoto et al..$^{30}$ investigated MEP elicited in paraspinal muscles of four Japanese patients with HAM/TSP recorded at the Th3, Th6, Th9 and Th12 vertebral levels. They found prolonged MEP latencies bilaterally and decreased conduction velocity of thoracic spinal cord between Th3 and Th12. On the other hand, MEP obtained with HIVES found prolonged CMCT in LL but not in UL of Japanese patients investigated by Ugawa et al. ${ }^{34,40}$ and by Tomita et al. ${ }^{36,37}$ with no clinical correlations reported. Investigations done in the Ivory Coast found CMCT prolongation in UL and LL but no clinical correlations were reported either ${ }^{35,41}$.

\section{HIV}

Three studies ${ }^{25,31,32}$ reported abnormalities in the CMCT of HIV positive patients. However, two of them ${ }^{25,31}$ found such abnormalities while patients were doing voluntary muscle contraction. Moglia et al. ${ }^{25}$ found a CMCT prolongation that ranged from $44 \%$ to $72 \%$ of patients tested, though it was not clear whether these abnormalities correlated with clinical symptoms since the data from both neurologically asymptomatic and symptomatic patients were pooled. Zandrini et al..$^{31}$ investigated HIV seropositive and seronegative intravenous drug addicted (IVDA) subjects and matched them with healthy controls. HIV seronegative IVDA patients had normal CMCT but seropositive patients had prolonged CMCT in $46.1 \%$ and $47.3 \%$ with clinical symptoms classified as CDC stage II and stage III respectively ${ }^{31}$. Patients having prolonged $\mathrm{CMCT}$ progressed to successive stages of disease in higher proportion than those having normal CMCT. According to the authors, " $73 \%$ of CDC group II and $55 \%$ of CDC group III having abnormal CMCT values tended to progress more rapidly to AIDS stages"31. No clinical clue was given to understand the progression rate noted. The third study reporting abnormalities was done by Parisi et al. ${ }^{32}$, who found up to $20 \%$ CMCT abnormalities; however the scarcity of data published did not allow for a more detailed analysis. These studies contrasted with others ${ }^{24,27,42,43}$ that did not find CMCT abnormalities in neurologically asymptomatic and symptomatic patients despite up to three years of follow up with some patients [42]. On the other hand, Moglia et al. ${ }^{25}$, applied HIVES to 87 patients who had mixed clinical CDC stages and also found a prolongation of CMCT. Correlation with TMS studies or clinical findings obtained from the same group of patients was not done.

\section{DISCUSSION}

This study shows interesting similarities and differences in the neurological effects of the so-called human retroviruses in the neural transmission of human corticospinal tracts. In HTLV-I affected patients, the main abnormality was the delay of CMCT due to major corticospinal tract involvement between lower cervical and lumbar spinal cord (Figure) ${ }^{29,38}$ in regions controlling LL with less involvement at cervical levels. These abnormal, albeit consistent, findings on HAM/TSP fit well with the abnormalities around the mid-thoracic and lumbar regions found in neuroimaging and pathological investigations described elsewhere on this disorder ${ }^{44}$. In these latter studies, it has been demonstrated that the main lesion is atrophy of lateral columns at around the thoracic level ${ }^{45,46}$.

TMS abnormalities in HAM/TSP were considered not due to peripheral nerve conduction dysfunction, which, if present, follows a vasculitic-like mechanism ${ }^{47,48}$, nor due to axonal damage clearly observed in pathological reports ${ }^{49,50}$ but rather as mild slowing cortico-lumbar and cortico-cervical pathways and increased probability of multiple sites of demyelinization in longer axons ${ }^{28}$, in a rostro-caudal progression of disease reaching cervical spinal cord late in disease progression. However, some patients debut with the disease at the cervical spinal cord level, leaving still unanswered the issue of whether this is a primary or secondary finding in the disease process ${ }^{8,51}$. The lack of a relationship of MEP abnormal findings with "chronic" but not with "moderate" involvement, suggested a critical point of degeneration of neural pathways involved with motor responses in HAM $/ \mathrm{TSP}^{28}$.

The extension of the disease process is still under debate. With TMS, some studies showed pyramidal tract involvement correlated with abnormalities in the posterior columns of the spinal cord measured by somatosensory evoked potentials but not in others. In the first case, a widespread inflammation reaching the posterior columns was considered ${ }^{39}$. Others suggested that the involvement of posterior and lateral columns is an independent degenerative process. We would favor the first hypotheses because it has been demonstrated, in recent neuropathological research that the entire CNS is affected simultaneously ${ }^{46,52}$. Thus, the lack of correlation between CMCT obtained by TMS and somatosensory evoked potentials, in some groups of patients, could be due more to disease duration than the anatomical distribution of the lesion.

Clinical correlations were uneven due to lack of ap- 


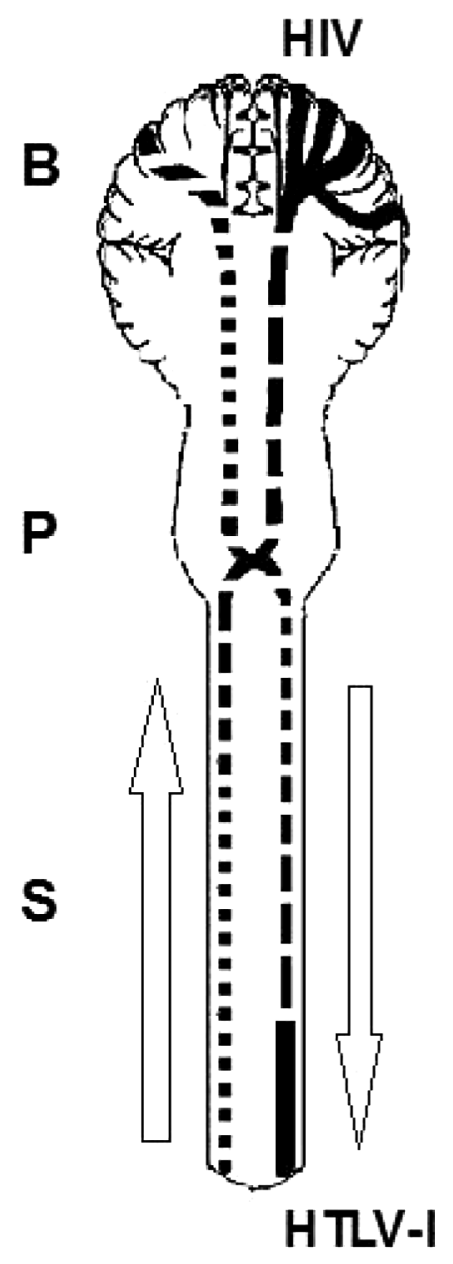

Figure. Schematic representation of the corticospinal tract involvement in AIDS and HAM/TSP. In AIDS, brain is more affected than lower spinal cord in a top to down direction, and in HAM/TSP the involvement is larger at lower levels of the spinal cord and it decreases following a down to top direction. B: brain; P: pons; S: spinal cord.

propriate measures in some studies or failure to study patients with a standard clinical scale. However, TMS might be useful to monitor disease progression and therapeutic measures, mostly at earlier stages of disease, when impaired axonal flow just starts and long before a ceiling effect of degeneration has appeared ${ }^{28}$.

Despite the fact that axonal changes happen early in disease in $\mathrm{HAM} / \mathrm{TSP}^{49,50}$, the demyelination process as well as the clinical course described throughout the years resembles multiple sclerosis ${ }^{53,54}$. MEP abnormalities in paraspinal muscles were found consistently abnormal, the lesion being more bilateral in HAM/TSP compared to multiple sclerosis; however, the small sample of patients investigated precluded advancing conclusions about the paraspinal involvement of HAM/TSP ${ }^{30,45}$. In any event, CMCT, and likely, conduction velocity to paraspinal muscles obtained with TMS, may be added to the laboratory investigations suggested elsewhere ${ }^{9,45,53,54}$ in helping differentiate these two disorders, mostly in places where they could overlap in the general population ${ }^{55-58}$.

In HIV-seropositive subjects, CMCT abnormalities were not found as consistently as in HTLV-I seropositive patients. Indeed, motor pathway involvement was null in some series while others detected abnormalities in up to $72 \%$. However, some of the abnormalities reported suggest a supraspinal involvement due very likely to lack of inhibitory silent period-like mechanisms ${ }^{59}$. In two groups ${ }^{25,31}$, abnormal CMCT was obtained while subjects were performing a voluntary muscle contraction, which modifies neural transmission due to modulatory effects on intracortical connections, neurotransmitters and neural structures involved with corticomotor output. Voluntary muscle contraction also recruits interneuronal populations other than those tested in relaxed muscles ${ }^{59}$; thus, it is very likely that these CMCT abnormalities are actually due to higher central nervous system abnormalities (Figure) involving D or I waves ${ }^{19}$, among other mechanisms. However, more work on this is needed. In any event, pyramidal tract abnormalities were considered due to an early demyelinating process and as an early marker of disease ${ }^{31}$. Some authors ${ }^{43}$ considered that fever could be the factor for having normal results since increasing the temperature turns normal the abnormal neural transmission ${ }^{60}$; however, this was shown not to be the case ${ }^{43}$.

Co-morbidities and some immunological stressors ${ }^{61-67}$ may also account for the discrepancies found in this study. In this line, mycotoxins such as aflatoxins which are strong immunosuppressant growing in foods abnormally store $^{68,69}$ were found in recreational drugs used by drug addicts at risk of AIDS $^{70}$ and in patients with TSP living in southwestern Colombia ${ }^{69}$; such neurotoxins ultimately may modify TMS responses due to a bystander mechanism ${ }^{65,69,71}$.

In the same view, pathological reports showed clear dorsal and lateral spinal cord involvement in HIV positive patients, resembling vitamin B12 depletion-like findings ${ }^{14}$, and some patients included in this study had secondary nutritional disturbances which modify $\mathrm{CMCT}^{25,66,67,72}$. Other studies indicate that patients with AIDS have a myriad of infections and are affected by different toxic substances including recreational drugs all of which may cloud final interpretations. Indeed, HIV positive patients who were drug addicts had white and gray matter abnormalities in early states of disease, probably due to drug consumption and lifestyle ${ }^{73}$, and it modifies TMS measures as well. Supporting this, chronic cocaine users had higher motor thresholds at cortical levels and lack of long latency inhibition investigated with paired pulsed techniques obtained 
by TMS due to probable abnormal GABAergic transmission and cell membrane sodium channels dysfunction ${ }^{74,77}$.

Therefore, we consider that the aforementioned factors, cofactors and stressors, among others ${ }^{2,58,61,62,65}$ could co-vary with endogenous or exogenous retroviruses modifying AIDS and HAM/TSP clinical course $e^{69,76}$ as well as TMS measures ${ }^{25,42}$ in still unknown and untested forms. And they may account for some or all of the uneven results discussed above. Likewise, such co-factors may also explain contradictory findings reported in other contradictory neurophysiological studies of retroviruses-associated neurological disorders which have not had clear pathophysiological explanation ${ }^{78-80}$.

Moreover, the discrepancies reported in this study, and very likely in others, may also be the result of considerable variation in the inclusion criteria, stimulation protocols, outcome measures, overall design, clinical stage of patients, numbers of subjects and inadequate control groups studied. Further, important technical considerations on coil orientation, stimuli strength either electrical or magnetic, type of coil, and lack of more appropriate serological criteria, among others factors ${ }^{19,81,82}$ would ultimately affect human clinical neurobiological studies of corticospinal tracts in retroviruses research.

Besides the CMCT measurements discussed above, more sophisticated and sensitive TMS measures that detect early changes in thalamocortical-basal ganglia circuitry ${ }^{20,83,84}$ such as cortical thresholds, recruitment curves, silent periods, and excitatory and inhibitory phenomena produced by short and long interval stimulation obtained by single and paired magnetic stimulation are worth trying in HIV asymptomatic patients as well as in HTLV-I carriers at times when the fastest corticospinal fibers remain uninvolved ${ }^{11,12,24,76,85-89}$. This can be done in order to better understand cortico-cortical and neurotransmitter dysfunction early in disease development ${ }^{90}$, and it will also allow the application of more appropriate and effective neuromodulatory measures long before the fatal clinical AIDS or HAM/TSP appears.

\section{REFERENCES}

1. Shaw GM, Harper ME, Hahn BH, et al. HTLV-III infection in brains of children and adults with AIDS encephalopathy. Science 1985;227:177-182.

2. Leon-Sarmiento FE (ed). ViH \& los virus de la imaginacion humana. Bogota: Celsus, 2001.

3. Price RW, Brew B, Sidtis J, et al. The brain in AIDS: central nervous system HIV infection and AIDS dementia complex. Science 1988;239:586-592.

4. Gessain A, Barin F, Vernant JC, et al. Antibodies to human T-lymphotropic virus type-I in patients with tropical spastic paraparesis. Lancet 1985;8452:407-410.

5. Osame M, Usuku K, Izumo S, et al. HTLV-I associated myelopathy, a new clinical entity. Lancet 1986;8488:1031-1032.

6. Román GC, Osame M. Identity of HTLV-I-associated tropical spastic paraparesis and HTLV-I-associated myelopathy. Lancet 1988;8586: 651.

7. Leon-S FE. Clinical neurophysiology of HAM/TSP. In: Zaninovic V, Galindo J, Blank A (Eds). HTLV-I and related diseases. Cali: XYZ 1992: 97-102.
8. Leon-Sarmiento FE, Calderon A, Hernandez HG. Two Babinski signs in seropositive (HAM) and seronegative tropical spastic paraparesis. Arq Neurosiquiatr 2008;66:695-697.

9. Arimura K, Rosales R, Osame M, Igata A. Clinical electrophysiologic studies of HTLV-I-associated myelopathy. Arch Neurol 1987;44:609-612.

10. Iwasaki Y, Sawada K, Aiba I, et al. Widespread active inflammatory lesions in a case of HTLV-I-associated myelopathy lasting 29 years. Acta Neuropathol 2004;108:546-551.

11. Leon-S FE, Arimura K, Arimura Y, Sonoda Y, Osame M. Contralateral early blink reflex in patients with HTLV-I associated myelopathy/tropical spastic paraparesis. J Neurol Sci 1995;128:51-57.

12. Leon-S FE, Arimura K, Arimura Y, Suwazono S, Osame M. A clinica neurophysiological comparative study of HAM/TSP. Arch Med Res 1995;26:397-403.

13. McArthur JC. Neurologic manifestations of AIDS. Medicine 1987;66: 407-437.

14. Petito CK, Navia BA, Cho ES, et al. Vacuolar myelopathy pathologically resembling subacute combined degeneration in patients with the acquired immunodeficiency syndrome. N Engl J Med 1985;312:874-879.

15. Smith T, Jakobsen J, Trojaborg W. Myelopthy and HIV infection. AIDS 1990;4:589-591.

16. Barker AT, Jalinous R, Freeston IL. Non-invasive magnetic stimulation of human motor cortex. Lancet 1985;8437:1106-1107.

17. Amassian VE, Maccabee PJ. Transcranial magnetic stimulation. Conf Proc IEEE Eng Med Biol Soc 2006;1:1620-1603.

18. Merton PA, Merton HB. Stimulation of the cerebral cortex in the intact human subject. Nature 1980;285:227.

19. Hallett M. Transcranial magnetic stimulation: a primer. Neuron 2007; 55:187199.

20. Edwards MJ, Talelli P, Rothwell JC. Clinical applications of transcranial magnetic stimulation in patients with movement disorders. Lancet Neurol 2008;7:827-840.

21. Di Lazzaro V, Oliviero A, Profice P, et al. The diagnostic value of motor evoked potentials. Clin Neurophysiol 1999;110:1297-1307.

22. Chen R, Cros D, Curra A, et al. The clinical diagnostic utility of transcranial magnetic stimulation: report of an IFCN committee. Clin Neurophysiol 2008;119:504-532.

23. Hallett M. Transcranial magnetic stimulation and the human brain. Nature 2000;406:147-150.

24. Arendt G, Maecker HP, Jablonowski H, Hömberg V. Magnetic stimulation of motor cortex in relation to fastest voluntary motor activity in neurologically asymptomatic HIV-positive patients. J Neurol Sci 1992;112:76-80.

25. Moglia A, Zandrini C, Alfonsi E, Rondanelli EG, Bono G, Nappi G. Neurophysiological markers of central and peripheral involvement of the nervous system in HIV-infection. Clin Electroencephalogr 1991;22:193-198.

26. Claus D. Central motor conduction: method and normal results. Muscle Nerve 1990;13:1125-1132.

27. McAllister RH, Hems MV, Harrison MJG, et al. Neurophysiological assessment of peripheral nerve and spinal cord function in asymptomatic HIV-1 infection: results from the UCMSM/Medical Research Council neurology cohort. J Neurol 1995;242:406-414.

28. Young RE, Morgan OS, Forster A. Motor pathway analysis in HAM/TSP using magnetic stimulation and F-waves. Can J Neurol Sci 1998;25:48-54.

29. Andrade DO. Somatosensitive and motor evoked potentials in HTLV-I associate myelopathy. Arq Neuropsiquiatr 2005;63:843-846.

30. Hashimoto T, Uozumi T, Tsuji S. Paraspinal motor evoked potentials by magnetic stimulation of the motor cortex. Neurology 2000;55:885-888.

31. Zandrini C, Ciano C, Alfonsi E, Sandrini G, Minoli L, Moglia A. Abnormalities of central motor conduction in asymptomatic HIV-positive patients. Significance and prognostic value. Acta Neurol (Napoli) 1990;12:296-300.

32. Parisi L, Calandriello E, Terracciano M, Valente G, Amabile GA. Analysis of central motor pathways with CCT study in HIV infections. Electroencephalogr Clin Neurophysiol 1992;82:27-28.

33. Parra-Piñeros JE, Valderrama V, Leon-Sarmiento FE, et al. False-positive human immunodeficiency virus tests and trypanosome cruzi infection in eastern Colombia. South Med J 2004;97:423-424.

34. Ugawa Y, Kohara N, Shimpo T, Mannen T. Central motor and sensory conduction in adrenoleukomyeloneuropathy, cerebrotendinous xanthomatosis, HTLV-1-associated myelopathy and tabes dorsalis. J Neurol Neurosurg Psychiatry 1988;51:1069-1074.

35. Hugon J, Giordano C, Dumas M, et al. Evoked motor potentials in patients with tropical spastic paraplegia. In: Roman GC, Vernant JC, Osame M (Eds). HTLV-I and the nervous system. New York: Alan R Liss 1989:195-198. 
36. Tomita I, Shibayama K, Matsuo H, et al. Central motor conduction time in patients with HTLV-1 associated myelopathy. Acta Neurol Scand 1989;79:419-427.

37. Tomita I, Motomura M, Nagasato K, et al. Central motor conduction time (CCT) in patients with human T lymphotropic virus type I associated myelopathy (HAM). In: Roman GC, Vernant JC, Osame M (Eds). HTLV-I and the nervous system. New York: Alan R. Liss 1989:98-102.

38. Suga R, Tobimatsu S, Kira J, Kato M. Motor and somatosensory evoked potential findings in HTLV-I associated myelopathy. J Neurol Sci 1999; 167:102-106.

39. Shimizu H, Shiga Y, Fujihara K, Ohnuma A, Itoyama Y. Clinical and physiological significance of abnormally prolonged central motor conduction time in HAM/ TSP. J Neurol Sci 2001;185:39-42.

40. Ugawa Y, Kohara N, Shimpo T, Mannen T. Central sensory and motor conduction in adrenoleukodystrophy (ALD), cerebrotendinous xanthomatosis (CTX), HTLV-1-associated myelopathy (HAM) and tabes dorsalis. Rinsho Shinkeigaku 1988;28:819-827.

41. Hugon J, Giordano C, Dumas M, et al. Evoked motor potentials in patients with tropical myeloneuropathies. Neurology 1987;37(Suppl 1):S363.

42. McAllister RH, Herns MV, Harrison MJ, et al. Neurological and neuropsychological performance in HIV seropositive men without symptoms. J Neurol Neurosurg Psychiatry 1992;55:143-148.

43. Grapperon J, Trousset A, Jaubert D. Central and peripheral nervous system motor conduction rate in HIV infection. Presse Med 1993;22:1302-1306.

44. Osame M, Nakagawa M, Umehara F, et al. Recent studies on the epidemiology, clinical features and pathogenic mechanisms of HTLV-I associated myelopathy (HAM/TSP) and other diseases associated to HTLV. J Neurovirol 1997;3 (Suppl):S50-S51.

45. Arimura K, Arimura Y, Moritoyo H, et al. How helpful is thoracic paraspinal EMG in HAM/TSP. Muscle Nerve 1995;18:248-250.

46. Izumo S, Umehara F, Osame M. HTLV-I-associated myelopathy. Neuropathology 2000;20(Suppl):S65-S68

47. Arimura K, Arimura Y, Tokimura Y, et al. Neuropathy in HTL-I associated myelopathy (HAM). Electroencephal Clin Neurophysiol 1993; 87(Suppl):S61.

48. Kiwaki T, Umehara F, Arimura Y, et al. The clinical and pathological features of peripheral neuropathy accompanied with HTLV-I associated myelopathy. J Neurol Sci 2003;206:17-21.

49. Umehara F, Izumo S, Nakagawa M, et al. Immunocytochemical analysis of the cellular infiltrate in the spinal cord lesions in HTLV-I-associated myelopathy. J Neuropathol Exp Neurol 1993;52:424-430.

50. Umehara F, Abe M, Koreeda Y, et al. Axonal damage revealed by accumulation of beta-amyloid precursor protein in HTLV-I-associated myelopathy. J Neurol Sci 2000;176:95-101.

51. Umehara F, Nagatomo S, Yoshishige K, et al. Chronic progressive cervical myelopathy with HTLV-I infection: variant form of HAM/TSP? Neurology 2004;63:1276-1280

52. Aye MM, Matsuoka E, Moritoyo T, et al. Histopathological analysis of four autopsy cases of HTLV-I-associated myelopathy/tropical spastic paraparesis: inflammatory changes occur simultaneously in the entire central nervous system. Acta Neuropathol 2000;100:245-252.

53. Leon-S FE, Arimura K, Osame M. Multiple sclerosis and HTLV-I associated myelopathy are two distinct clinical entities. Multi Scler 1996;2: 88-90.

54. Puccioni-Sohler M, Yamano Y, Rios M, et al. Differentiation of HAM/ TSP from patients with multiple sclerosis infected with HTLV-I. Neurology 2007;68:206-213.

55. Sanchez JL, Aguirre OM, Arcos-Burgos I, et al. Prevalence of multiple sclerosis in Colombia. Rev Neurol 2000;31:1101-1103.

56. Castro-Costa CM, Carton H, Santos TJ. HTLV-I negative tropical spastic paraparesis: a scientific challenge. Arq Neuropsiquiatr 2001;59:289-294.

57. Pradilla G, Leon-Sarmiento FE. Esclerosis multiple en Colombia: cerrando la brecha. Acta Neurol Col 2007;23:3-5.

58. Zaninovic V, Leon-S FE. Fifteen years of follow-up on HTLV-I positive and HTLV-I negative spastic paraparesis patients in southwestern Colombia, Southamerica. J Neurovirol 1996;2:357-360.

59. Werhahn KJ, Behrang-Nia M, Bott MC, Klimpe S. Does the recruitment of excitation and inhibition in the motor cortex differ? J Clin Neurophysiol 2007;24:419-423.

60. Denys EH. The influence of temperature in clinical neurophysiology. Muscle Nerve 1991;14:795-811.

61. Duesberg P. AIDS data. Science 1995;268:350-352.

62. Duesberg PH. The role of drugs in the origin of AIDS. Biomed Pharmacother 1992;46:3-15.

63. Leon-S FE, Carpintero M, Bayona J, et al. La falta de refrigeracion y la intoxicación por micotoxinas son cofactores fundamentales en la paraparesia espastica tropical. Rev Neurol 1998;152:564-567.

64. Leon-S FE, Rivera SA, Vargas EJ, Van Bentum A \& Grupo ASINO-HIV: Sida en Santander ¿ malas interpretaciones, falta de recursos.o que?. Acta Med Col 1998;23(Suppl):S243.

65. Leon-Sarmiento FE, Carpintero M. Retrovirus, micotoxinas, inmunosupresion and neurodegeneration. Rev Neurol 2002;35:562-571.

66. Misra UK, Kalita J. Comparison of clinical and electrodiagnostic features in B12 deficiency neurological syndromes with and without antiparietal cell antibodies. Postgrad Med J 2007;83:124-127.

67. Leon-S FE, de Castro Costa CM, Gaffga N. Discrepancy, coincidence or evidence in chronic idiopathic spastic paraparesis throughout the world. Arq Neuropsiquiatr 1997;55:530-535.

68. Tamer SK, Misra S, Jaiswal S. Central motor conduction time in malnourished children. Arch Dis Child 1997;77:323-325.

69. Anthony IC, Arango JC, Stephens B, Simmonds P, Bell JE. The effects of illicit drugs on the HIV infected brain. Front Biosci 2008;13:1294-1307.

70. Leon-S FE, Ariza-Deleon A, Leon ME, Ariza-C A. Peopling the Americas. Science 1996;273:723-724

71. Leon-S FE, Carpintero M, Gaffa N, Ocampo L, Bayona J. Mycotoxins in myelopathies of man. Lancet 1996;348:1039.

72. Hendrickse RG, Maxwell SM. Heroin addicts, AIDS, and aflatoxins. Br Med J (Clin Res Ed) 1988;296:1257.

73. Leon-Sarmiento FE, Bayona-Prieto J, Leon-S ME. Micotoxinas, mielopatias y mucho mas en, para y desde Colombia. Rev Sal Pub 2007;9:315-316.

74. Boutros NN, Lisanby SH, Tokuno H, et al. Elevated motor threshold in drug-free, cocaine-dependent patients assessed with transcranial magnetic stimulation. Biol Psychiatry 2001;49:369-373.

75. Boutros NN, Lisanby SH, McClain-Furmanski D, et al. Cortical excitability in cocaine-dependent patients: a replication and extension of TMS findings. J Psychiatr Res 2005;39:295-302.

76. Nath A, Maragos WF, Avison MJ, et al. Acceleration of HIV dementia with methamphetamine and cocaine. J Neurovirol 2001;7:66-71.

77. Sundaresan K, Ziemann U, Stanley J, et al. Cortical inhibition and excitation in abstinent cocaine-dependent patients: a transcranial magnetic stimulation study. Neuroreport 2007;18:289-292.

78. Jabbari B, Russo MB, Russo ML. Electroencephalogram of asymptomatic adult subjects. Clin Neurophysiol 2000;111:102-105.

79. Nuwer MR. Asymptomatic HIV infection does not cause EEG abnormalities: results from the Multicenter AIDS Cohort Study (MACS). Neurology 1992;42:1214-1219.

80. Pierelli F, Soldati G, Zambardi P, et al. Electrophysiological study (VEP, BAEP) in HIV-1 seropositive patients with and without AIDS. Acta Neurol Belg 1993;93:78-87.

81. Leon-S FE, Pradilla G. Antero-posterior location of the pyramidal tract in the internal capsule in an alive patient. Inv Clin 1994;35:67-75.

82. Ugawa Y, Kanazawa I. Motor-evoked potentials: unusual findings. Clin Neurophysiol 1999;110:1641-1645.

83. Bakshi R. Neuroimaging of HIV and AIDS related illnesses: a review. Front Biosci 2004;9:632-646.

84. Bohlhalter S, Leon-Sarmiento FE, Hallett M. Abnormal motor cortex excitability in peripheral injury associated focal dystonia. Mov Dis 2007; 22:1186-1189.

85. Arendt G, Hefter H, Elsing C, et al. Motor dysfunction in HIV-infected patients without clinically detectable central-nervous deficit. J Neurol 1990;237:362-368.

86. Baldeweg T, Catalan J, Pugh K, et al. Neurophysiological changes associated with psychiatric symptoms in HIV-infected individuals without AIDS. Biol Psychiatry 1997;41:474-487.

87. Koutsilieri E, Sopper S, Scheller C, ter Meulen V, Riederer P. Parkinsonism in HIV dementia. J Neural Trasm 2002;109:767-775.

88. Morgan DJ, Caskey MF, Abbehusen C, et al. Brain magnetic resonance imaging white matter lesions are frequent in HTLV-I carriers and do not discriminate from HAM/TSP. AIDS Res Hum Retroviruses 2007; 23:1499-1504.

89. Silva MT, Mattos P, Alfano A, Araújo AQ. Neuropsychological assessment in HTLV-1 infection: a comparative study among TSP/HAM, asymptomatic carriers, and healthy controls. J Neurol Neurosurg Psychiatry 2003;74:1085-1089.

90. Lopez OL, Smith G, Meltzer CC, Becker JT. Dopamine systems in human immunodeficiency virus-associated dementia. Neuropsychiatry Neuropsychol Behav Neurol 1999;12:184-192.

91. Berger JR, Arendt G. HIV dementia, the role of the basal ganglia and dopaminergic systems. J Psychopharmacol 2000;14:214-221. 